\title{
Mapping glacier-related research in polar regions: a bibliometric analysis of research output from 1987 to 2016
}

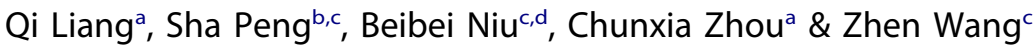

${ }^{a}$ Chinese Antarctic Centre of Surveying and Mapping, Wuhan University, Wuhan, China; ${ }^{b} S c h o o l$ of Economics and Environmental Resources, Hubei University of Economics, Wuhan, China; 'School of Resource and Environmental Sciences, Wuhan University, Wuhan, China; ${ }^{d}$ College of Resources and Environment, Shandong Agricultural University, Taian, China

\begin{abstract}
We carried out a bibliometric analysis of literature related to glaciers in polar regions from the period 1987-2016 indexed in the Science Citation Index Expanded database. A comprehensive review was performed by analysing the research output trends, publication categories, main journals, leading countries and their collaborations, leading scientists, author keywords and Keywords Plus. The results indicated that the number of publications related to glaciers in polar regions has increased rapidly. The USA and several European countries, including the UK, France, Germany and Switzerland, are the leaders in the field of glacial studies, as reflected both in the productivity measures and in the distribution of core scientists. Quaternary Science Reviews, the Journal of Glaciology, and Geophysical Research Letters were the most productive journals for glacial studies. The synthesized analysis of the keywords demonstrated the current research emphases and hinted at future research trends. Reconstructing past climate changes through studies of ice-core records is one of the most important research subjects. Numerical modelling has become a commonly used tool in polar region glacial research. A better understanding of the responses of glaciers to widespread climatic warming is needed now and in the future.
\end{abstract}

\section{KEYWORDS}

publications; climate change; ice-core records

\section{ABBREVIATIONS}

CAGR: compound annual growth rate; CNRS: France's National Center for Scientific Research (Centre National de la Recherche Scientifique); GR: growth rate; $p$-index: performance index; SCIE: Science Citation Index Expanded; TC: total citations to glacier-related articles in a given journal or by a given author; TP: total number of glacier-related articles in a given journal or by a given author; TC/TP: average citations per glacier-related article in a given journal or by a given author

\section{Introduction}

Glacial ice covers $10 \%$ of the land area on Earth at present, approximately one-third of its maximum since the last ice age. Glaciers store approximately $75 \%$ of the world's fresh water and therefore are an important freshwater resource and a major contributor to ongoing sea-level rise (Vaughan et al. 2013). In addition, glaciers preserve a remarkable record of past climatic and atmospheric conditions on Earth and provide a potential source of information for better understanding past environmental changes. The study of glaciers also has great significance for predicting future climate and environmental changes.

Modern glacial studies originated in the mid-20th century. Mountain glaciers first attracted the interest of scientists because they were closer to human habitats than the glaciers located in Antarctica or Greenland. However, nearly $76 \%$ of the global glacier areas are located in polar regions (RGI Consortium 2017) and with the advent of remote sensing techniques, and other technological and logistical advances, we have been able to measure the dynamics of glaciers in these less accessible parts of the world. As amplifiers of global climate change, polar regions balance the heat budget of the world and play a pivotal role in shaping the global environment (Smetacek \& Nicol 2005). Therefore, the study of glaciers in polar regions has become emphasized in recent decades (Cuffey \& Paterson 2010). Various aspects of glaciers in polar regions have been studied, including glacier length and area changes (Murray et al. 2003; Pfeffer 2007; WGMS 2008; Citterio et al. 2009; Thomson et al. 2011; Carrivick et al. 2012), glacier volume and mass changes (Kaser et al. 2006; Howat et al. 2007; Rignot et al. 2008), the relationship between glacial mass loss and sea-level rise (Leclercq et al. 2011; Marzeion et al. 2012; Gardner et al. 2013), glacial response to climate change (Davies et al. 2014), glacial ecosystems (Price 2000; Wadham et al. 2012) and ice-core analysis (Jouzel et al. 2007; Steffensen et al. 2008). Moreover, scientists can reconstruct the history of a glacier and predict its future from numerical models

CONTACT Chunxia Zhou zhoucx@whu.edu.cn Chinese Antarctic Centre of Surveying and Mapping, Wuhan University, 129 Luoyu Road, Wuhan 430079, China

(4) Supplemental data for this article can be accessed here. 
(Pollard \& DeConto 2009; Joughin et al. 2010). The growing number of publications indicates that polar glaciers and the associated issues of climate change have been one of the more exceptional scientific interests in recent years.

Bibliometrics offers an effective tool to quantitatively reveal scientific progress through publications (e.g., from annual outputs, main journals, and leading countries and institutions) and qualitatively reveal the progress (e.g., hotspots and future research method directions) in different fields ( $\mathrm{Li}$ et al. 2011; Fu et al. 2013). With bibliometrics, previous studies have summarized the development of Antarctic research regarding spatiotemporal, national and categorical outputs; international collaborations; and the temporal evolution of keywords (Dastidar \& Ramachandran 2008; Ji et al. 2014). More recently, based on highly cited articles from Antarctic field research from 1900 to 2012, Fu \& Ho identified the research emphases by keywords, and characterized the citation patterns and citation lifespan (Fu \& Ho 2016). Glacier-related studies have also been summarized from different aspects (Eyles 1993; Lambeck \& Chappell 2001; Benn et al. 2007; Hodson et al. 2008; Sigman et al. 2010) without bibliometrics. To the best of our knowledge, few attempts have been made to demonstrate the development trends in past and current research with an emphasis on glacier-related research in polar regions.

In this study, we carried out an in-depth analysis of publications in the period 1987-2016 associated with glaciers in polar regions by using conventional bibliometric methods as well as social network analysis for visualizing the collaboration and the co-word distribution. The target of this paper is to answer three critical questions that have been previously unaddressed. (1) What are the temporal patterns of glacier-related scientific publications during the past 30 years? (2) Who were the core authors in glacier-related research? (3) What topics were most investigated in the past, and what are the future research emphases?

\section{Data sources and methodology}

For the bibliometric analysis, the online version of the SCIE bibliographic database (updated on 10 May 2017) was searched with keywords ("* glacier*" or "* glacia*") and ("polar" or "Antarctic*" or "South Pole" or "North Pole" or "Arctic*" or "Greenland") as topics for all years of publications between 1987 and 2016. All records were manually checked by a domain expert to exclude non-related topics, such as "glacialin", "glacialist" and "glacialis". The terms listed above retrieved the clear majority of glacier-related publications in polar regions.

CAGR and GR were utilized to characterize the subject categories of the glacier research. GR was defined as the total number of publications in a certain category during 2002-2016 divided by the number during 1987-2001. CAGR was calculated based on the following formula (Niu et al. 2014):

$$
\operatorname{CAGR}\left(t_{0}, t_{n}\right)=\left(N\left(t_{n}\right) / N\left(t_{0}\right)\right)^{\frac{1}{t_{n}-t_{o}}}-1,
$$

in which $t_{0}$ is the baseline year for a certain category (ranging from 1987 to 1993), $t_{n}$ is the ending year (2016) and $N\left(t_{n}\right)$ and $N\left(t_{0}\right)$ represent the number of publications for a certain category in 2016 and $t_{0}$, respectively.

Two indicators were used to evaluate the academic influence of the journals. The average citation (TC/TP) is a mature indicator for comparing the academic quality of journals. Furthermore, the $p$-index, which provides a balance between quality (TC/TP) and quantity (TC), was introduced to give a comprehensive evaluation for the journals (Prathap 2010). It is defined as:

$$
p=\left(\frac{T C^{2}}{T P}\right)^{1 / 3}
$$

where TP represents the total number of publications in a given journal and TC is the the total citations to articles in a given journal, respectively.

The number of published papers and the cited frequency were used to identify the core authors. According to Lotka's Law, the lowest standard for evaluating a core author is the number of publications $\left(M_{p}\right)$ and citations $\left(M_{C}\right)$ that reach the values calculated by the following formulas (Ding 1993):

$$
M_{P}=0.749 \times \sqrt{N_{\max }}
$$

and

$$
M_{C}=0.749 \times \sqrt{C_{\max }},
$$

in which $N_{\max }$ and $C_{\max }$ represent the number of publications by the most prolific author and the record of the most highly cited author during the last 30 years. The values of $M_{p}$ and $M_{C}$ should be rounded to the nearest integer.

The calculations for all indices were processed in Microsoft Excel 2010. An international collaboration network was constructed according to the author affiliations and then visualized using Gephi. The temporal evolution of keywords during a given time span was analysed using a social network analysis. Moreover, to identify the main research stream, a modularity class algorithm was used for the constructed co-keyword matrix to classify keywords into different clusters and those visualized using Gephi.

\section{Results and discussion}

\section{Research output trend}

Related publications totalling 16,378 were retrieved from the SCIE database during the study period, covering 13 document types. Of these publications, 92.3\% were original articles. All publications were used for 
further analysis as relevant citable items. Figure 1 presents the research output regarding both global and polar glaciers during 1987-2016. The number of publications on global glaciers has increased rapidly in the past 30 years. A similar increase was found for polar glacier studies. Specifically, the annual number of publications in polar glacier research increased from 20 in 1987 to 1246 in 2016, with a steeper rise in the average annual growth rate $(15.3 \%)$ than that of global glacier-related research (10.2\%). The proportion of polar glacier publications showed an upward trend from $7.69 \%$ in 1987 to $26.8 \%$ in 2000 , and kept stable from then on. This result may imply that researchers have paid more attention to polar glacier studies over recent decades since the capabilities for glacier monitoring have been improved dramatically.
The volume of publications in polar glacier research doubled approximately every five or six years during the study period. This is in excellent agreement with the growth trend of the number of publications on climate change reported by Haunschild et al. (2016). The overall number of SCIE publications increased by a factor of less than three in the time period 1987-2016, demonstrating a much slower growth rate than polar glacier-related publications.

\section{Identification of subject categories and journals}

Glacier research has covered 63 subject categories during the past 30 years. The top 15 most productive categories are presented in Table 1. The three most common categories were Geology $(9627,58.8 \%$ of the

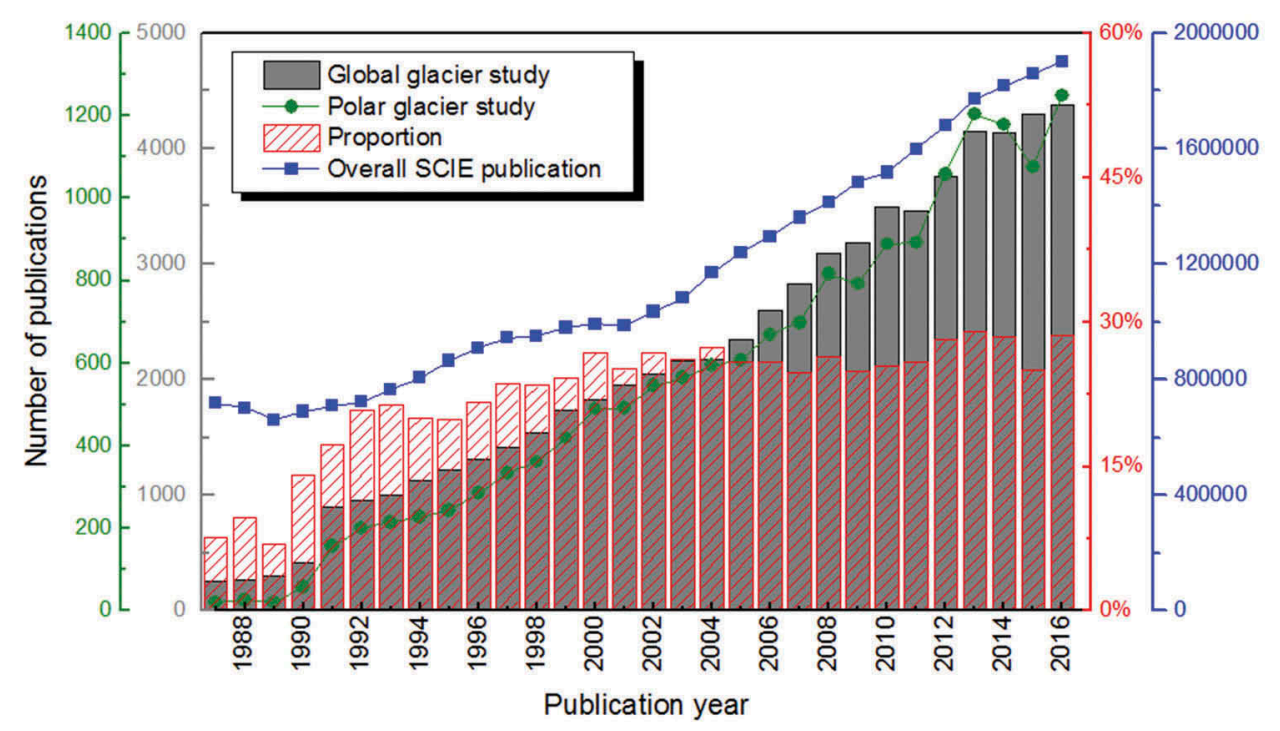

Figure 1. Evolution of the number of publications in global (both polar and non-polar) and polar glacier studies.

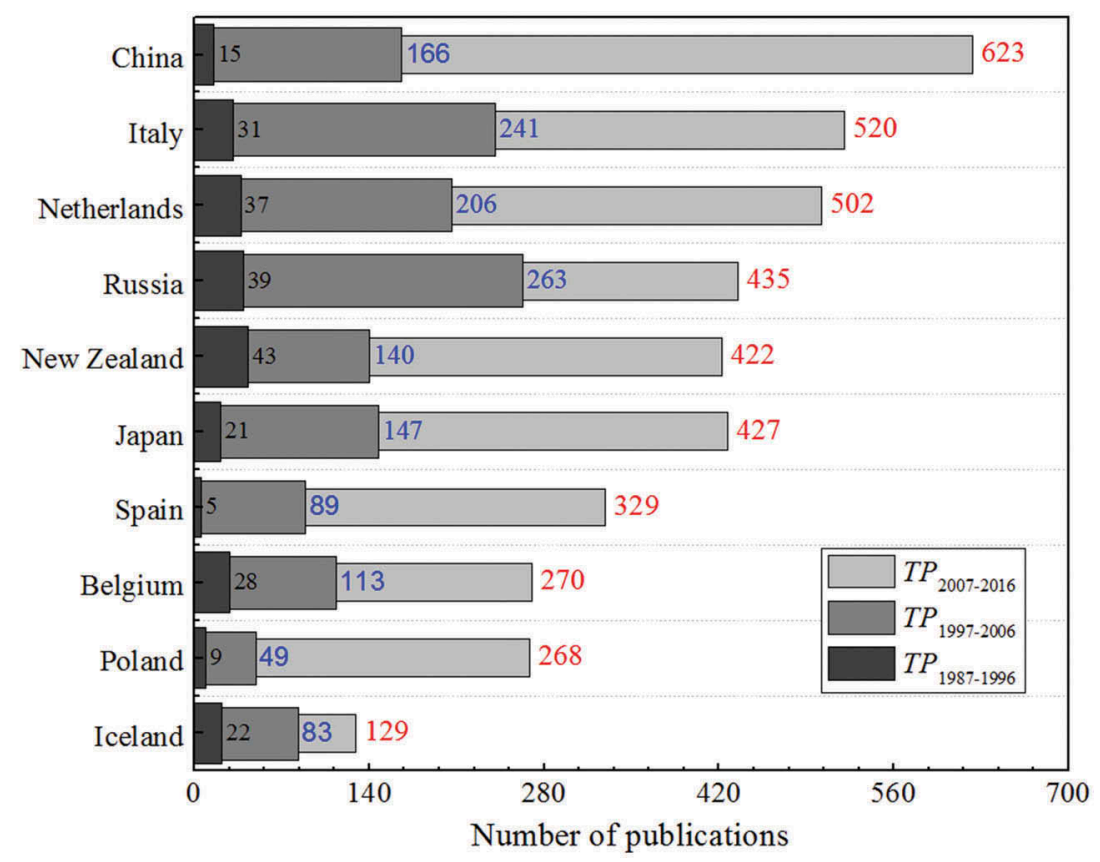

Figure 2. Publications of 10 countries with respect to the time-trend analysis during 1987-2016. 


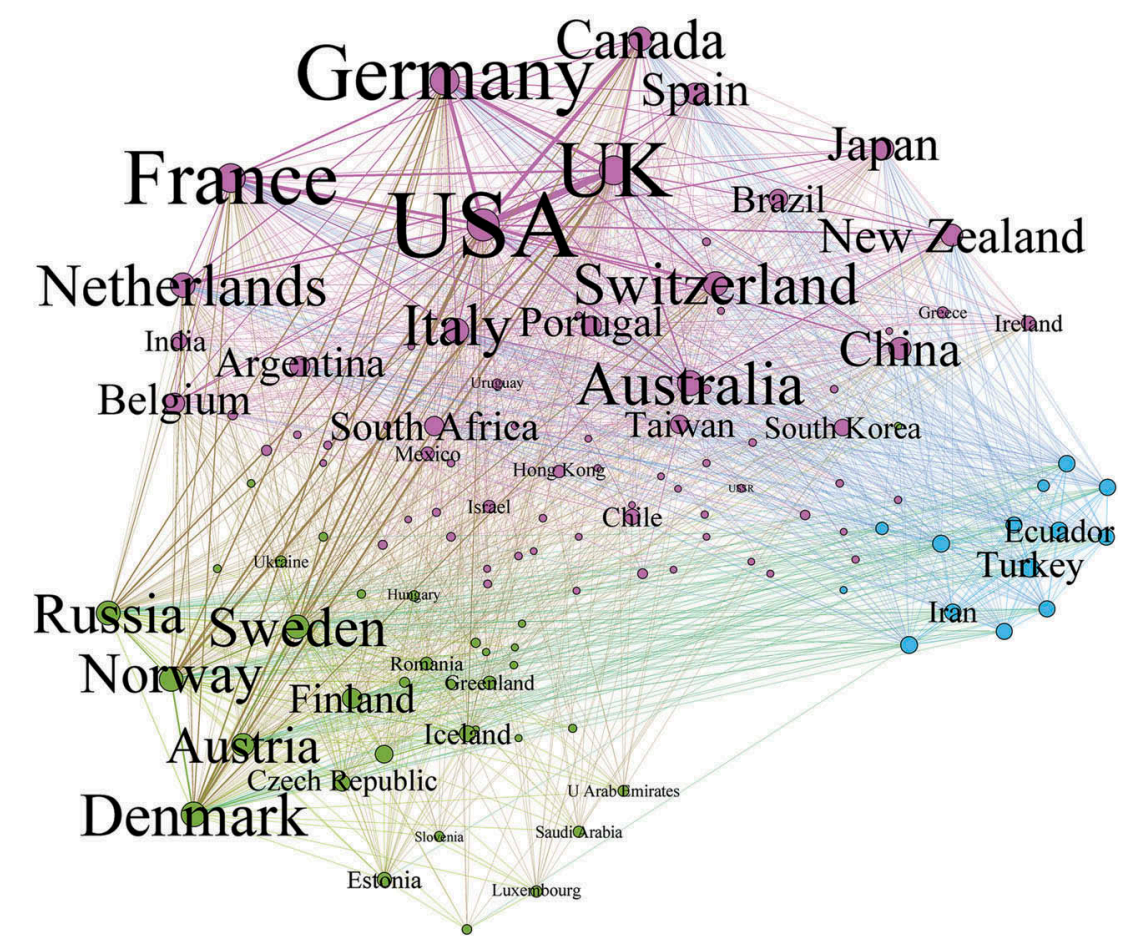

Figure 3. Collaboration network among the top 50 most active countries/territories.

total), Physical Geography $(5075,31.0 \%)$ and Environmental Sciences/Ecology (2102, 12.8\%), followed by Geochemistry/Geophysics (1501; 9.17\%) and Oceanography (1474; 9.00\%). This result implies that glacier studies spanning multiple disciplines require close cooperation among researchers from different fields.

The GR and CAGR of the top 15 categories were calculated to identify the most quickly rising categories (Table 1). In terms of the GR index, Microbiology leaped to the first position, far ahead of the second category. This result indicates the sharply growing interest in the glacier-associated ecosystem in the last 15 years. On the glacier surface, plenty of sunlight and liquid water make it possible for a diverse consortium of microbes to live, such as bacteria, algae and phytoflagellates (Anesio \& Laybourn-Parry 2012). In subglacial environments, the ecosystem is characterized by

Table 1. The top 15 subject categories with the most publications.

\begin{tabular}{llcc}
\hline Subject categories & Rank (TP) & GR & CAGR (\%) \\
\hline Geology & $1(9627)$ & 3.60 & 14.9 \\
Physical geography & $2(5075)$ & 3.73 & 16.9 \\
Environmental sciences ecology & $3(2102)$ & 4.18 & 19.7 \\
Geochemistry geophysics & $4(1501)$ & 3.41 & 16.0 \\
Oceanography & $5(1474)$ & 2.54 & 11.3 \\
Palaeontology & $6(1473)$ & 2.38 & 9.9 \\
Meteorology atmospheric sciences & $7(1255)$ & 3.63 & 16.1 \\
Science technology other topics & $8(1031)$ & 3.00 & 12.2 \\
Marine freshwater biology & $9(414)$ & 3.45 & 12.1 \\
Evolutionary biology & $10(296)$ & 4.29 & 10.5 \\
Microbiology & $11(281)$ & 24.5 & 17.0 \\
Biodiversity conservation & $12(153)$ & 5.33 & 10.9 \\
Remote sensing & $13(249)$ & 5.73 & 13.5 \\
Engineering & $14(248)$ & 5.70 & 8.1 \\
Water resources & $15(236)$ & 5.05 & 10.9 \\
\hline
\end{tabular}

bacteria and viruses (Hodson et al. 2008). As a biome with unique life adaptations, glacial ecosystems are sensitive to climate change. Microtechniques and biotechnology are advancing by leaps and bounds, giving new impetus to glacial ecosystem research in recent years. The category of Remote Sensing was ranked second in terms of the GR index. The development of satellite remote sensing techniques, which provide a completely new way to observe glaciers, have allowed glaciers in remote places to be measured and their dynamics studied. In contrast, the CAGR index provided smooth growth rates that were free from the annual fluctuations of numbers of publications (Niu et al. 2014). In the CAGR analysis, Environmental Sciences/Ecology was ranked at the top, followed by the categories of Microbiology, Physical Geography, Meteorology/ Atmospheric Sciences and Geochemistry/Geophysics, categories all with continuous increases from 1987 to 2016. This result demonstrates the long-term growth of the Environmental Sciences/Ecology category compared to the dramatic increase in the Microbiology category in recent years.

Publications appeared in a wide range of the 646 journals analysed. The top 10 most active journals are summarized in Table 2 according to their TP, TC/TP, $p$-index, Web of Science category and journal rank within their category. With 1105 glacier-related publications, Quaternary Science Reviews has published the most glacier-related publications, accounting for $6.75 \%$ of the total glacier-related publications. It is followed by the Journal of Glaciology (686, 4.19\%), Geophysical Research Letters $(587,3.58 \%)$ and Paleoceanography (507, 3.10\%). The $p$-index is a comprehensive indicator for quantifying 
Table 2. Performance of the 10 most active journals.

\begin{tabular}{|c|c|c|c|c|}
\hline Journal & $\operatorname{TP}\left(\%^{\mathrm{a}}\right)$ & $\mathrm{TC} / \mathrm{TP}$ & $p$-index & Web of Science category (rank) \\
\hline Quaternary Science Reviews & $1105(6.75)$ & 42.0 & 125 & $\begin{array}{l}\text { Physical Geography (3/49) } \\
\text { Geosciences Multidisciplinary (10/184) }\end{array}$ \\
\hline Journal of Glaciology & $686(4.19)$ & 25.8 & 77.1 & $\begin{array}{l}\text { Physical Geography }(11 / 49) \\
\text { Geosciences Multidisciplinary }(31 / 184)\end{array}$ \\
\hline Geophysical Research Letters & $587(3.58)$ & 33.3 & 86.7 & Geosciences Multidisciplinary (13/184) \\
\hline Paleoceanography & $507(3.10)$ & 47.6 & 105 & $\begin{array}{l}\text { Geosciences Multidisciplinary }(25 / 184) \\
\text { Oceanography }(6 / 61) \\
\text { Paleontology }(1 / 54)\end{array}$ \\
\hline Annals of Glaciology & $475(2.90)$ & 15.6 & 48.6 & $\begin{array}{l}\text { Physical Geography (31/49) } \\
\text { Geosciences Multidisciplinary }(100 / 184)\end{array}$ \\
\hline Earth and Planetary Science Letters & $468(2.86)$ & 40.1 & 90.9 & Geochemistry \& Geophysics (7/81) \\
\hline Palaeogeography Palaeoclimatology Palaeoecology & $437(2.67)$ & 28.1 & 70.1 & $\begin{array}{l}\text { Physical Geography (16/49) } \\
\text { Geosciences Multidisciplinary (44/184) } \\
\text { Paleontology (4/54) }\end{array}$ \\
\hline Geology & $311(1.90)$ & 47.7 & 89.1 & Geology $(1 / 47)$ \\
\hline Global and Planetary Change & $308(1.88)$ & 28.3 & 62.7 & $\begin{array}{l}\text { Physical Geography (8/49) } \\
\text { Geosciences Multidisciplinary (22/184) }\end{array}$ \\
\hline Cryosphere & $282(1.72)$ & 17.8 & 44.6 & $\begin{array}{l}\text { Physical Geography (2/49) } \\
\text { Geosciences Multidisciplinary (7/184) }\end{array}$ \\
\hline
\end{tabular}

${ }^{a}$ Ratio of the number of publications in a given journal to the total number of publications.

the scientific productivity of journals based on both citations and publications (Prathap 2010). Quaternary Science Reviews and Paleoceanography had the highest $p$-index values of 125 and 105, respectively. Geology and Paleoceanography had the highest TC/TP (average number of citations per paper) values of 47.7 and 47.6 , respectively. However, we should note that TC/TP may need to be further normalized with regard to different subject categories if we want to accurately evaluate the journals only by the average number of citations.

\section{International productivity and collaboration}

The 20 most productive countries/territories are listed in Table 3. The USA, ranked the most productive country, accounted for $22.0 \%$ of the total publications, followed by the UK and Germany with a contribution of $13.0 \%$ and $7.74 \%$ of the total publications, respectively. During 1987-2016, the USA, the UK and Germany also had the top three highest quality indices (h-index), indicating that they had broad and deep interest in glaciers. This was also consistent with the most productive countries for climate-change research as ranked by Haunschild et al. (2016), except for China. China ranked fifth for the climate-change publications (Haunschild et al. 2016), while in our study it only ranked 11th for glacier-related publications. Regarding the average number of citations, Iceland, Switzerland and France stood in the highest places.

Over the past 30 years, the top 10 most active countries maintained a stable growth rate in glacier studies, while the second 10 most active countries demonstrated a different growth pattern. The productivity of the second 10 most active countries for each of the 10year intervals is depicted in Fig. 2. China exhibited the most notable growth in the past decade, rising from 20th place during 1987-1996 to ninth place during 2007-2016 in terms of total publications. This may be attributed to the increased scientific research funding from the government and the establishment of Chinese research stations in the Arctic and Antarctic since 1984. China's h-index (58) was ranked only 15 th, indicating its impact should be further strengthened.

The core position of these most prolific countries/ territories could also be observed in terms of their pivotal roles in the collaboration network (Fig. 3). The network was composed of 123 countries. The node of the network represented a country/territory, and it was scaled by the degree of centrality. The links represent the collaboration between any pair of nodes, scaled the by the frequency of the collaborations. Table 3 lists the degrees and weighted degrees for each country/territory.

It can be observed from the high-density links that collaborations among these 20 productive countries were tight. The USA has the dominant position in the collaboration network and the broadest coopera-

Table 3. Top 20 most active countries/territories in glacierrelated research.

\begin{tabular}{llcccc}
\hline $\begin{array}{l}\text { Countries/ } \\
\text { territories }\end{array}$ & Rank $\left(\%{ }^{\mathrm{a}}\right)$ & $\begin{array}{c}\text { TC/ } \\
\text { TP }\end{array}$ & h-index & Degree & $\begin{array}{c}\text { Weighted } \\
\text { degree }\end{array}$ \\
\hline USA & $1(22.0)$ & 44.2 & 206 & 91 & 6612 \\
UK & $2(13.0)$ & 38.1 & 151 & 80 & 5376 \\
Germany & $3(7.74)$ & 40.6 & 132 & 80 & 3909 \\
Canada & $4(6.35)$ & 34.0 & 107 & 61 & 2214 \\
France & $5(5.52)$ & 50.8 & 127 & 79 & 3016 \\
Norway & $6(4.34)$ & 36.9 & 99 & 61 & 2275 \\
Denmark & $7(3.60)$ & 46.7 & 97 & 65 & 2341 \\
Australia & $8(3.40)$ & 33.1 & 86 & 66 & 1736 \\
Sweden & $9(2.97)$ & 42.8 & 89 & 61 & 1894 \\
Switzerland & $10(2.91)$ & 58.5 & 101 & 64 & 1886 \\
China & $11(2.77)$ & 21.7 & 58 & 56 & 936 \\
Italy & $12(2.73)$ & 26.9 & 59 & 64 & 1494 \\
Netherlands & $13(2.56)$ & 40.3 & 80 & 64 & 1574 \\
Russia & $14(2.54)$ & 33.3 & 72 & 62 & 1312 \\
New Zealand & $15(2.08)$ & 26.6 & 63 & 55 & 1139 \\
Japan & $16(2.05)$ & 29.3 & 58 & 54 & 1044 \\
Spain & $17(1.46)$ & 28.0 & 55 & 53 & 940 \\
Belgium & $18(1.41)$ & 43.2 & 63 & 50 & 1004 \\
Poland & $19(1.12)$ & 14.5 & 33 & 40 & 341 \\
Iceland & $20(0.806)$ & 83.1 & 54 & 34 & 567 \\
\hline
\end{tabular}

${ }^{a}$ Ratio of the number of publications in a country to the total number of publications. 
tion with all other productive countries. The UK, France, Germany and Canada also have open cooperation with other countries. Particularly, the cooperation between the USA and the UK is the tightest. Another cluster was formed by Sweden, Norway, Denmark, Russia, Austria, Finland, Iceland, etc. There has been more frequent cooperation within the cluster, possibly because they are all European countries and mainly members of the Arctic Council, a high-level intergovernmental forum for the sustainable development and environmental protection of the Arctic countries, indigenous communities and inhabitants.

\section{Leading scientists}

In total, 10964 authors have contributed publications on glacier-related research. It is necessary for researchers to gain insight into authors with a relatively high importance. There are no standard ways for identifying the core authors. Herein, two methods, the number of published papers and the number of citations of a published paper (Wang et al. 2012), were used to identify the core authors. Based on the $\mathrm{M}_{\mathrm{P}}$ and $\mathrm{M}_{\mathrm{C}}$ values calculated using Eqns. 3 and 4, 959 core authors with 10 or more papers and a frequency of over 115 citations were identified. The top 21 leading authors and their affiliation information are listed in Supplementary Table S1. However, it is worth noting that this evaluation method is also relatively rough, for it does not take into consideration the subject differences, the different active period of researchers and the varied range of research interests. Therefore, it just provides a rough picture of the researchers, rather than an in-depth and comprehensive evaluation of the leading scientists.

Authors such as J. Jouzel, J.A. Dowdeswell, R.B. Alley, J. Chappellaz, V. Masson-Delmotte, E. Rignot, J.R. Petit, H. Fischer and T.F. Stocker are ranked as the most productive and highly cited authors. Generally, their research has focused on how the glaciers respond to climate change either in the past or in the future. These leading scientists are mainly from Europe (seven out of nine). Particularly, researchers from the CNRS accounted for a large proportion (four out of nine).

Among the most prolific authors, J.A. Dowdeswell, at the University of Cambridge, contributed the most papers (158), followed by J. Jouzel, at the CNRS (152), R.B. Alley, at Pennsylvania State University (126), M.J. Siegert, at the University of Bristol (120), and E. Rignot, at the University of California Irvine (109). In addition to prolificacy, J. Jouzel, R.B. Alley and J. A. Dowdeswell also achieved the highest h-index. T.F. Stocker, at the University of Bern and J. Chappellaz, at the CNRS, were also noteworthy for their high average citations of over 148 and h-index values of over 41. In contrast, authors such as M. Pagani, at Yale University,
S.J. Johnsen and J.P. Steffensen at the University of Copenhagen, and D. Raynaud and J.M. Barnola, at the CNRS, have the top-ranked average citations $(\geq 199)$.

\section{Research trends and hotspots}

To capture the major research trends and hot issues, the temporal evolution of the keywords and keyword clusters was analysed. The author keywords were combined with KeyWords Plus, since they both provide a relatively comprehensive overview of the research trends. Hereafter, we referred to them as keywords for simplicity.

A total of 33159 keywords were listed in the 15949 articles, with a total of 181097 occurrences. As revealed in other bibliometric studies (Chuang et al. 2007), the frequencies and rankings of keywords followed a power-law distribution with a good correlation (Supplementary Fig. S1). The results showed that $62.4 \%$ out of the 33159 keywords appeared only once, and $84.9 \%$ keywords appeared less than the average frequency (five times). The large number of keywords used less than 10 times (92.2\%) might be related to discontinuities in the research or a diverse research focus. The keyword clustering analysis provides a reasonably detailed panorama of glacier-related research.

\section{Hot topics and trends}

The frequency of keywords was statistically analysed to identify the research trends and development (Chiu \& Ho 2007). Supplementary Table S2 lists the 30 most frequently used keywords during 1987-2016, accounting for $14.8 \%$ of the total occurrences. Keyword ranking changes and frequencies in the three 10-year intervals are indicative of changes in the trending fields.

Over the study period, other than search terms "Antarctica", "Arctic", "glacier" and "Greenland", the top five most frequently used keywords were "climate change" (1457, 4.39\%), "climate" (1362, 4.11\%), "ice sheet" (1268, 3.82\%), "Last Glacial Maximum" (1214, $3.66 \%)$ and "record" $(1213,3.66 \%)$. The count of palaeoclimatology-related research increased rapidly. For example, the counts of "Late Pleistocene", "Last Glacial Maximum", "Holocene", and "ice core" rose from 17, 9, 31 and 37 in the first 10 years to $365,904,467$ and 419 in the last 10 years, respectively. Ice cores may provide the most direct and highly resolved records of atmospheric parameters. By looking at small samples of the ancient atmosphere entombed in bubbles or the well-preserved multiple proxies of the past environmental conditions in an ice core, it is possible to generate continuous reconstructions of a past climate (Augustin et al. 2004). Although the deep ice cores from Antarctica from recent years offered researchers more chances to reconstruct the past climate, the percentage of "record" declined from $1.58 \%$ in $1987-1996$ to $0.443 \%$ in $2007-2016$. We 
speculate that this result occurred because of its relatively low growth rate compared to other keywords, such as "model". This may reflect the fact that deep ice-core sampling requires tremendous financial and technical inputs, whereas computer models benefit from increasing computer power and are more easily available. Different types of proxy records, such as ice cores and sediments, have been widely used in models to capture temperature information from a long time ago (Ljungqvist 2009). Meanwhile, the increasing ranking of "model" indicated that mathematical models have been widely used by researchers in investigating how glaciers responded to climate change in the past and how future glaciers may behave under different scenarios (Davies et al. 2014). The development of computing power in recent decades, as well as observation methods, offers further support for complex mathematical modelling.

Increasing research interest in "mass balance", "temperature" and "flow" was clearly observed, which are all related to the dynamic changes of a glacier. Research articles on glacier dynamics increased rapidly in the whole study period, reflecting our interest in glacier mass loss, particularly in Antarctica and Greenland, and rising sea level. However, the count of articles discussing issues related to "sea level" grew more slowly than the others, resulting in a declining proportion. The rank of "ocean" kept decreasing during the three intervals, from fifth to $23 \mathrm{rd}$. These trends demonstrated that ice-ocean interaction processes became a research hotspot some time ago, but the development of this research area has not been as fast as the others. In terms of a specific study area, "West Antarctica", which ranked eighth $(0.559 \%)$ in the last 10 years, has attracted the most attention on account of its unstable state and recent rapid change (Lee et al. 2012; Rignot et al. 2013; Turner et al. 2017).

There was a noteworthy trend regarding the two main keywords "climate" and "climate change". "Climate" received relatively less attention than "climate change" in the period from 2007 to 2016 compared to the first two 10-year periods from 1997 to 2006. This indicates that the scientific community has not been satisfied with just investigating past climate through polar region glacier research: they wanted to fully understand how glaciers will respond to future climate change.

\section{Keyword clustering analysis}

In addition to the research hotspots, a clustering analysis was undertaken to examine the comprehensive relationships between keywords and to identify the main research streams by using Gephi software. Keywords that appeared more than four times (18.5\% of the total keywords) were used for a clustering analysis because they are closely related to the main research streams of the polar glaciers. The network was first displayed by using a Force
Atlas2 Layout. Then we performed the community detection and colourized clusters according to the "modularity class" value of each keyword. The Louvain method is implemented in Gephi software for the community detection procedure. This stateof-the-art method uses the similar information to categorize major clustering as other methods (e.g., k-means) (Koopman \& Wang 2017). Finally, we checked the clusters with a domain expert and properly explained the clustering results.

To better visualize the temporal evolution of the keywords clusters, we divided the whole study time span into three periods (Fig. 4). The clusters of different periods varied in size and partially overlapped. This is because the boundaries between clusters are sometimes unclear (Velden et al. 2017; Wang \& Koopman 2017). In each cluster, the nodes represent high-frequency keywords, the size of which is proportional to its degree, and the large nodes represent the core themes in each 10-year period. Each cluster is marked with different colours.

In the period from 1987 to 1996 (Fig. 4a), the clusters with the central nodes of "record", "climate", "ages" and "sediments" had the biggest share, accounting for $26.14 \%$ of the total in-use keywords. This is followed by the clusters centred on "history", "ice sheet", "glaciation" and "ice" (22.06\%). Both clusters are strongly interconnected with palaeoclimatology, which is one of the most important research areas related to polar glaciers, as glaciers preserve an extraordinary record of Earth's past climate changes. The clusters containing similar keywords also occupied a large portion over the following 20 years. This trend indicated that reconstructing past climate changes has been one major glaciological research area over the past three decades. Another important cluster in the whole period focused on searelated keywords, including "North-Atlantic", "sea" and "ocean". This demonstrates the research interest in the strong interaction between the polar glaciers and the sea. At the ice-ocean interface, warm ocean currents can melt the ice at the grounding line and bottom of the ice shelf.

In Fig. 4b and c, the clusters centred on "Antarctica" and "Greenland" were much more obvious than those in Fig. 4a. Many keywords related to glacier dynamic changes were also more notable. This was attributed to the development of glacier observing methods, especially remote sensing techniques. The response of glaciers to climate forcing (e.g., changes in the glacier surface elevation and annual variations in the total mass or daily surface melt conditions) can be more easily measured with the assistance of remote sensing. Moreover, the large amount of data could reveal the complex processes at the glacier surface and bed and therefore help researchers to understand glacial dynamics. Furthermore, the strengthening of the cluster centred on "climate change", concomitant with the weakening of the "climate"-centred cluster, was also 


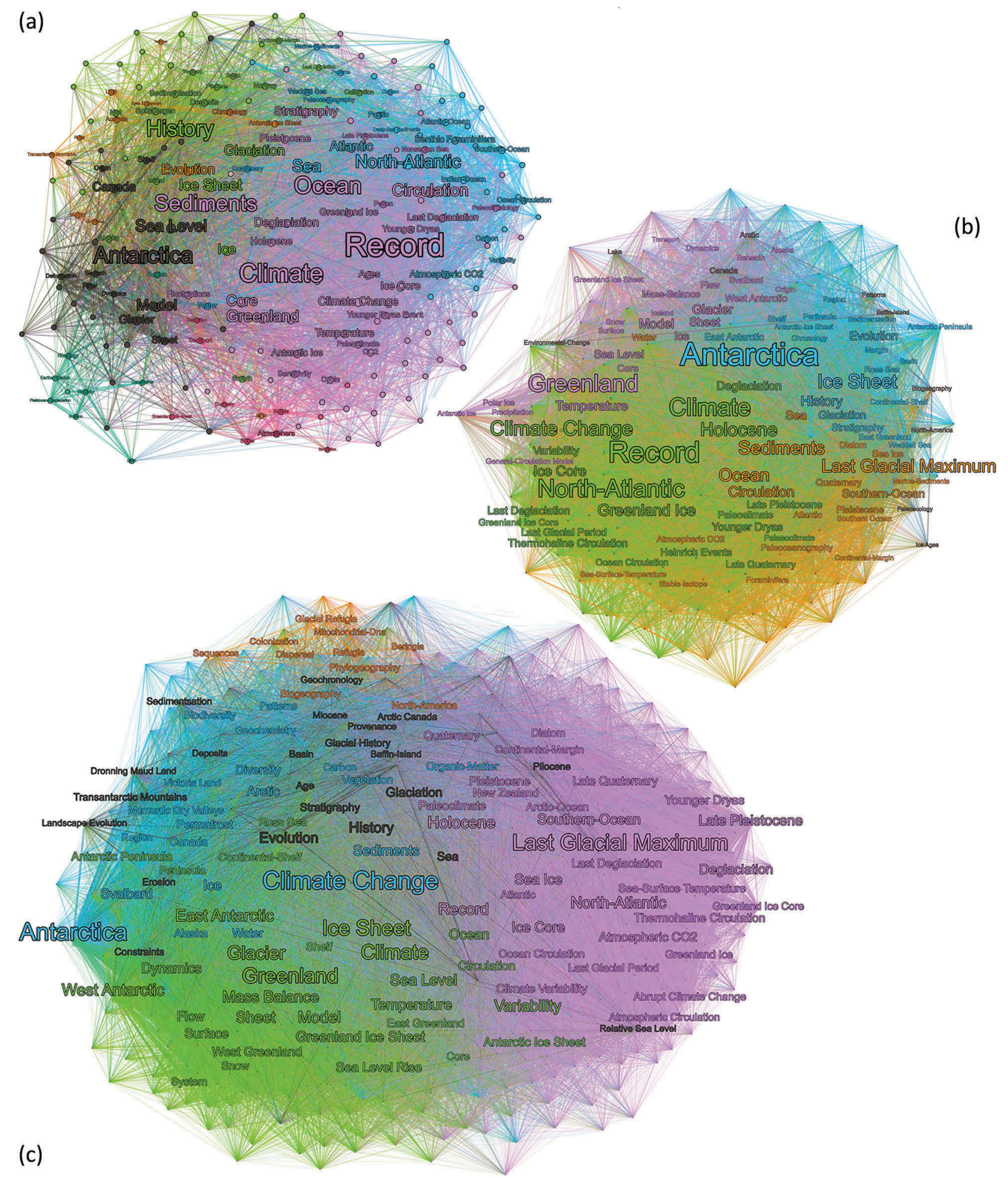

Figure 4. Keyword clusters during the research time span separated into three periods: (a) 1987-1996, (b) 1997-2006, and (c) 2007-2016.

worth noting. As global warming is being confirmed, how the ice on Earth will respond has become one of the most important questions. As basal conditions beneath fast-flowing outlet glaciers change, glacier flow accelerates, hastening the contribution of glaciers to global sealevel increases. The complex feedback mechanisms that are involved, both on the glacier bed and at the surface, need to be further investigated.
Overall, since the 1980s, the forefront of polar glacier research has shifted to the interface of geological and climatological science. The keyword "evolution" demonstrates the most important aspects of research regarding polar glaciers: by building a deeper understanding of past processes, temperatures and environmental conditions, we will be able to better understand how glaciers in 
the polar region will respond to climate change in the future.

\section{Conclusions}

Our studies highlight the rapid increase of the outcomes of polar glacial research in the last 30 years. Through a synthesized analysis of keywords, we found that reconstructing past climate changes from ice-core records was one of the most common applications of glacier studies. The huge amount of progress in computing power and observation methods in recent years has allowed researchers to apply complex numerical models to glacier research, such as evaluating the influence of changing the controlling variables or predicting glacial responses to climate change. Such developments have made numerical modelling a widely used tool in glacial research. Another important topic has been the dynamic changes of glaciers. The mass loss of glaciers will have a direct impact on human life by raising the sea level. These analyses revealed that understanding how glaciers respond to widespread climatic warming is an urgent question.

\section{Acknowledgements}

We like to thank two anonymous reviewers for their helpful and constructive comments. The authors would like to thank Professor Song Hong for his guidance on the bibliometrics.

\section{Disclosure statement}

No potential conflict of interest was reported by the authors.

\section{Funding}

This research is funded by the National Natural Science Foundation of China (grant numbers 41376187, 41776200), the Chinese Polar Environment Comprehensive Investigation \& Assessment Programme (CHINARE201602-04) and the Fundamental Research Funds for the Central Universities (2042015kf0189).

\section{References}

Anesio A.M. \& Laybourn-Parry J. 2012. Glaciers and ice sheets as a biome. Trends in Ecology \& Evolution 27, 219-225.

Augustin L., Barbante C., Barnes P.R.F., Barnola J.M., Bigler M., Castellano E., Cattani O., Chappellaz J., Dahl-Jensen D., Delmonte B., Dreyfus G., Durand G., Falourd S., Fischer H., Fluckiger J., Hansson M.E., Huybrechts P., Jugie R., Johnsen S.J., Jouzel J., Kaufmann P., Kipfstuhl J., Lambert F., Lipenkov V.Y., Littot G.V.C., Longinelli A., Lorrain R., Maggi V., Masson-Delmotte V., Miller H., Mulvaney R., Oerlemans J., Oerter H., Orombelli G., Parrenin F., Peel D.A., Petit J.R., Raynaud D., Ritz C., Ruth U., Schwander J., Siegenthaler U., Souchez R., Stauffer B., Steffensen J.P., Stenni B., Stocker T.F., Tabacco I.E.,
Udisti R., van de Wal R.S.W., van den Broeke M., Weiss J., Wilhelms F., Winther J.-G., Wolff E.W. \& Zucchelli M. 2004. Eight glacial cycles from an Antarctic ice core. Nature 429, 623-628.

Benn D.I., Warren C.R. \& Mottram R.H. 2007. Calving processes and the dynamics of calving glaciers. EarthScience Reviews 82, 143-179.

Carrivick J.L., Davies B.J., Glasser N.F., Nyvlt D. \& Hambrey M.J. 2012. Late-Holocene changes in character and behaviour of land-terminating glaciers on James Ross Island, Antarctica. Journal of Glaciology 58, 1176-1190.

Chiu W.T. \& Ho Y.S. 2007. Bibliometric analysis of tsunami research. Scientometrics 73, 3-17.

Chuang K.Y., Huang Y.L. \& Ho Y.S. 2007. A bibliometric and citation analysis of stroke-related research in Taiwan. Scientometrics 72, 201-212.

Citterio M., Paul F., Ahlstrom A.P., Jepsen H.F. \& Weidick A. 2009. Remote sensing of glacier change in West Greenland: accounting for the occurrence of surge-type glaciers. Annals of Glaciology 50, 70-80.

Cuffey K. \& Paterson W.S.B. 2010. The physics of glaciers. 4th edn. Burlington, MA: Butterworth-Heinemann/Elsevier.

Dastidar P.G. \& Ramachandran S. 2008. Intellectual structure of Antarctic science: a 25-years analysis. Scientometrics 77, 389-414.

Davies B.J., Golledge N.R., Glasser N.F., Carrivick J.L., Ligtenberg S.R.M., Barrand N.E., van den Broeke M.R., Hambrey M.J. \& Smellie J.L. 2014. Modelled glacier response to centennial temperature and precipitation trends on the Antarctic Peninsula. Nature Climate Change 4, 993-998.

Ding X. 1993. Literature metrology basis. Beijing: Peking University Press.

Eyles N. 1993. Earth's glacial record and its tectonic setting. Earth-Science Reviews 35, 1-248.

Fu H.Z. \& Ho Y.S. 2016. Highly cited Antarctic articles using Science Citation Index Expanded: a bibliometric analysis. Scientometrics 109, 337-357.

Fu H.Z., Wang M.H. \& Ho Y.S. 2013. Mapping of drinking water research: a bibliometric analysis of research output during 1992-2011. Science of the Total Environment 443, 757-765.

Gardner A.S., Moholdt G., Cogley J.G., Wouters B., Arendt A.A., Wahr J., Berthier E., Hock R., Pfeffer W.T., Kaser G., Ligtenberg S.R.M., Bolch T., Sharp M.J., Hagen J.O., van den Broeke M.R. \& Paul F. 2013. A reconciled estimate of glacier contributions to sea level rise: 2003 to 2009. Science $340,852-857$.

Haunschild R., Bornmann L. \& Marx W. 2016. Climate change research in view of bibliometrics. PLos One 11, e0160393, doi: 10.1371/journal.pone.0160393.

Hodson A., Anesio A.M., Tranter M., Fountain A., Osborn M., Priscu J., Laybourn-Parry J. \& Sattler B. 2008. Glacial ecosystems. Ecological Monographs 78, 41-67.

Howat I.M., Joughin I. \& Scambos T.A. 2007. Rapid changes in ice discharge from Greenland outlet glaciers. Science 315, 1559-1561.

Ji Q., Pang X. \& Zhao X. 2014. A bibliometric analysis of research on Antarctica during 1993-2012. Scientometrics 101, 1925-1939.

Joughin I., Smith B.E. \& Holland D.M. 2010. Sensitivity of 21 st century sea level to ocean-induced thinning of Pine Island Glacier, Antarctica. Geophysical Research Letters 37, L20502, doi: 10.1029/2010GL044819.

Jouzel J., Masson-Delmotte V., Cattani O., Dreyfus G., Falourd S., Hoffmann G., Minster B., Nouet J., Barnola J.M., Chappellaz J., Fischer H., Gallet J.C., Johnsen S., 
Leuenberger M., Loulergue L., Luethi D., Oerter H., Parrenin F., Raisbeck G., Raynaud D., Schilt A., Schwander J., Selmo E., Souchez R., Spahni R., Stauffer B., Steffensen J. P., Stenni B., Stocker T.F., Tison J.L., Werner M. \& Wolff E. W. 2007. Orbital and millennial Antarctic climate variability over the past 800,000 years. Science 317, 793-796.

Kaser G., Cogley J.G., Dyurgerov M.B., Meier M.F. \& Ohmura A. 2006. Mass balance of glaciers and ice caps: consensus estimates for 1961-2004. Geophysical Research Letters 33, L19501, doi: 10.1029/2006GL027511.

Koopman R. \& Wang S. 2017. Mutual information based labelling and comparing clusters. Scientometrics 111, 1157-1167.

Lambeck K. \& Chappell J. 2001. Sea level change through the last glacial cycle. Science 292, 679-686.

Leclercq P.W., Oerlemans J. \& Cogley J.G. 2011. Estimating the glacier contribution to sea-level rise for the period 1800-2005. Surveys in Geophysics 32, 519-535.

Lee H., Shum C.K., Howat I.M., Monaghan A., Ahn Y., Duan J.B., Guo J.Y., Kuo C.Y. \& Wang L. 2012. Continuously accelerating ice loss over Amundsen Sea catchment, West Antarctica, revealed by integrating altimetry and GRACE data. Earth Planetary Science Letters $321,74-80$.

Li J.F., Wang M.H. \& Ho Y.S. 2011. Trends in research on global climate change: a Science Citation Index Expandedbased analysis. Global Planet Change 77, 13-20.

Ljungqvist F.C. 2009. Temperature proxy records covering the last two millennia: a tabular and visual overview. Geografiska Annaler Series A, Physical Geography 91, 11-29.

Marzeion B., Jarosch A.H. \& Hofer M. 2012. Past and future sea-level change from the surface mass balance of glaciers. Cryosphere 6, 1295-1322.

Murray T., Strozzi T., Luckman A., Jiskoot H. \& Christakos P. 2003. Is there a single surge mechanism? Contrasts in dynamics between glacier surges in Svalbard and other regions. Journal of Geophysical Research-Solid Earth 108, article no. 2237, doi: 10.1029/2002JB001906.

Niu B., Loáiciga H.A., Wang Z., Zhan F.B. \& Hong S. 2014. Twenty years of global groundwater research: a Science Citation Index Expanded-based bibliometric survey (1993-2012). Journal of Hydrology 519, 966-975.

Pfeffer W.T. 2007. A simple mechanism for irreversible tidewater glacier retreat. Journal of Geophysical Research -Earth Surface 112, F03S25, doi: 10.1029/2006JF000590.

Pollard D. \& DeConto R.M. 2009. Modelling West Antarctic ice sheet growth and collapse through the past five million years. Nature 458, 329-332.

Prathap G. 2010. The 100 most prolific economists using the $p$-index. Scientometrics $84,167-172$.

Price P.B. 2000. A habitat for psychrophiles in deep Antarctic ice. Proceedings of the National Academy of Sciences of the United States of America 97, 1247-1251.

RGI Consortium. 2017. Randolph Glacier Inventory. A dataset of global glacier outlines: version 6.0. Technical report, global land ice measurements from space, Colorado. Digital media. doi: 10.7265/N5-RGI-60.

Rignot E., Bamber J.L., van den Broeke M.R., Davis C., Li Y.H., van de Berg W.J. \& van Meijgaard E. 2008. Recent Antarctic ice mass loss from radar interferometry and regional climate modelling. Nature Geoscience $1,106-110$.

Rignot E., Jacobs S., Mouginot J. \& Scheuchl B. 2013. Iceshelf melting around Antarctica. Science 341, 266-270.

Sigman D.M., Hain M.P. \& Haug G.H. 2010. The polar ocean and glacial cycles in atmospheric $\mathrm{CO}_{2}$ concentration. Nature 466, 47-55.

Smetacek V. \& Nicol S. 2005. Polar ocean ecosystems in a changing world. Nature 437, 362-368.

Steffensen J.P., Andersen K.K., Bigler M., Clausen H.B., Dahl-Jensen D., Fischer H., Goto-Azuma K., Hansson M., Johnsen S.J., Jouzel J., Masson-Delmotte V., Popp T., Rasmussen S.O., Rothlisberger R., Ruth U., Stauffer B., Siggaard-Andersen M.L., Sveinbjornsdottir A.E., Svensson A. \& White J.W.C. 2008. High-resolution Greenland ice core data show abrupt climate change happens in few years. Science 321, 680-684.

Thomson L.I., Osinski G.R. \& Ommanney C.S.L. 2011. Glacier change on Axel Heiberg Island, Nunavut, Canada. Journal of Glaciology 57, 1079-1086.

Turner J., Orr A., Gudmundsson G.H., Jenkins A., Bingham R.G., Hillenbrand C.D. \& Bracegirdle T.J. 2017. Atmosphere-ocean-ice interactions in the Amundsen Sea Embayment, West Antarctica. Reviews of Geophysics 55, 235-276.

Vaughan D.G., Comiso J.C., Allison I., Carrasco J., Kaser G., Kwok R., Mote P., Murray T., Paul F., Ren J., Rignot E., Solomina O., Steffen K. \& Zhang T. 2013. Observations: cryosphere. In T.F. Stocker et al. (eds.): Climate change 2013. The physical science basis. Contribution of Working Group I to the fifth assessment report of the Intergovernmental Panel on Climate Change. Pp. 317-382. Cambridge: Cambridge University Press.

Velden T., Boyack K.W., Gläser J., Koopman R., Scharnhorst A. \& Wang S. 2017. Comparison of topic extraction approaches and their results. Scientometrics $111,1169-1221$.

Wadham J.L., Arndt S., Tulaczyk S., Stibal M., Tranter M., Telling J., Lis G.P., Lawson E., Ridgwell A., Dubnick A., Sharp M.J., Anesio A.M. \& Butler C.E.H. 2012. Potential methane reservoirs beneath Antarctica. Nature 488, 633-637.

Wang F.F., Qiu J.P. \& Yu H.Q. 2012. Research on the cross-citation relationship of core authors in scientometrics. Scientometrics 91, 1011-1033.

Wang S. \& Koopman R. 2017. Clustering articles based on semantic similarity. Scientometrics 111, 1017-1031.

WGMS 2008. Global glacier changes: facts and figures. Zurich: United Nations Environment Programme and World Glacier Monitoring Service. 